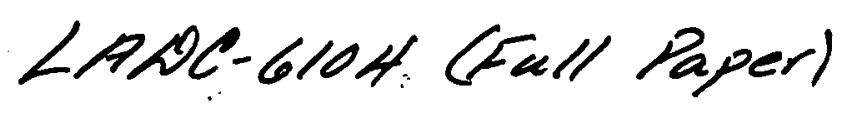

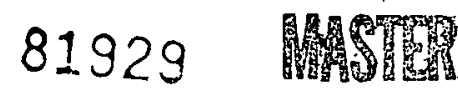
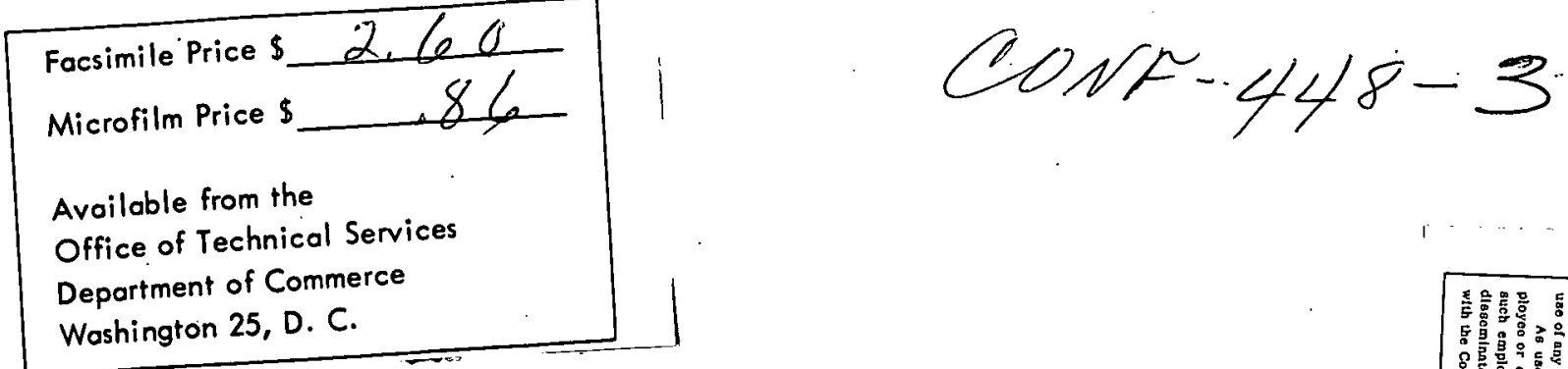

\section{PHYSIOLOGICAL PROPERTIES OF PLUTONIUM AND ASSESSMENT OF BODY BURDEN IN MAN}

By

Wright H. Langham

Los Alamos Scientific Laboratory University of California Los Alamos, New Mexico

\section{Introduction}

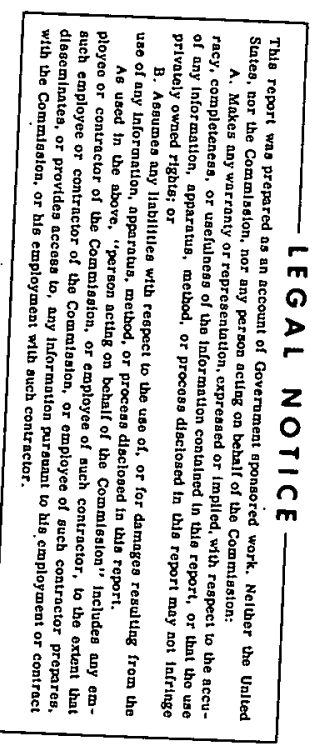

Historically, plutonium still may be considered a material of very recent vintage, having been discovered only 24 years ago by Seaborg, McMillan, Kennedy, and Wah1 [1]. Within a few months after discovery, the fissionable properties of the $\mathrm{Pu}^{239}$ isotope were established by the same group using an amount of material $(0.5 \mu \mathrm{g})$ equal to what is now considered to be approximately one maximum permissible body burden. In late 1942, Hamilton and coworkers [2] began studying the assimilation, distribution, and excretion of fission products and the heavy elements. Shortly thereafter, they observed that plutonium deposited in the bones of rats and postulated its similarity to radium in the production of bone sarcoma. From that time on, plutonium has been considered one of the most toxic substances known. Because of this early recognition of the potentially hazardous nature of plutonium, not one person is known to have been harmed by it other than under conditions resulting in criticality. Only 20 years have elapsed, however, since enough plutonium became available to create a potential industrial health problem. During this period, less 


\section{DISCLAIMER}

This report was prepared as an account of work sponsored by an agency of the United States Government. Neither the United States Government nor any agency Thereof, nor any of their employees, makes any warranty, express or implied, or assumes any legal liability or responsibility for the accuracy, completeness, or usefulness of any information, apparatus, product, or process disclosed, or represents that its use would not infringe privately owned rights. Reference herein to any specific commercial product, process, or service by trade name, trademark, manufacturer, or otherwise does not necessarily constitute or imply its endorsement, recommendation, or favoring by the United States Government or any agency thereof. The views and opinions of authors expressed herein do not necessarily state or reflect those of the United States Government or any agency thereof. 


\section{DISCLAIMER}

Portions of this document may be illegible in electronic image products. Images are produced from the best available original document. 
than 50 people are suspected of having accumulated body burdens equal to or greater than the maximum permissible level and, as was observed from the radium poisoning cases, a delay of from 12 to 30 years may be expected between time of exposure and appearance of symptoms of chronic radiation damage. In view of. the above circumstances, it is not surprising that a case of plutonium poịsoning has never been observed.

\section{Physiological Properties of Plutonium}

\subsection{Absorption and Modes of Exposure}

(a) Ingestion and Gastrointestinal Absorption.--Absorption of plutonium from the gastrointestinal tract has been studied in rats under a variety of conditions [3-5], including chronic administration in drinking water. Under the more usually anticipated conditions of exposure, absorption of $\mathrm{Pu}^{+4}$ is only about 0.003 per cent of the ingested dose. Hexavalent plutonium is absorbed at a somewhat higher rate than $\mathrm{Pu}^{+3}$ or $\mathrm{Pu}^{+4}$. Absorption of the lower valence states is increased by strong acidity and the presence of complexing agents such as citrate. There appears to be no mass effect when the amount of plutonium ingested is varied over a wide range. Very young animals absorb more than older ones by factors of 10 to 100. Gastrointestinal absorption has not been determined in man, but the pig with an anatomically similar digestive tract showed an absorption of only 0.002 per cent when administered $\mathrm{Pu}\left(\mathrm{NO}_{3}\right)_{4}$ solutions at $\mathrm{pH} 2$ [4]. Ingestion, therefore, is not considered to be a particularly significant mode of exposure.

(b) Absorption through the Unbroken Skin.--Only one experimental attempt (involving a single individual) to measure plutonium absorption through the intact human skin has been reported [6]. In this case, $\mathrm{Pu}\left(\mathrm{NO}_{3}\right)_{4}$ in $0.4 \underline{\mathrm{N}} \mathrm{HNO}_{3}$ was placed on the palmar surface and allowed to remain for several hours. Assay of urine samples during and for several days after the experiment showed no absorption within the limits of detection. All that could be said was that if absorption occurred, it was less than 
0.0002 per cent of. the amount applied per hour of contact. Wilson [7] reported an accidental exposure involving complete immersion for several minutes of the hand and wrist in a carbontetrachloride-tributyl phosphate solution containing 2 to $3 \mathrm{mc}$ of plutonium per ml. Prior to decontamination, total deposition on the hand was estimated as about $5 \mathrm{mc}$ and after one week was still $10 \mu \mathrm{c}$. Urine analysis suggested that total absorption through the skin was about 0.00002 per cent of the initial amount present on the skin surface. The Hanford group has reported a number of experiments on absorption of plutonium through the intact skin of rats [8-12]. These observations show that absorption is to some degree affected by the chemical form of the plutonium, nature of the solution, area exposed, and mass of plutonium applied. Acidity and nature of the solvent through irritation or other effects on the skin surface and complexing of the plutonium in soluble form tend to increase absorption. Because of the difference in physiological and anatomical properties of the rat and human skin, these results probably have little quantitative significance. Qualitatively, however, they may be significant in that conditions enhancing absorption through rat skin might enhance to some degree absorption through human skin also. As with gastrointestinal absorption, plutonium absorption through the intact skin under the more usually anticipated conditions appears not to be a particularly significant mode of exposure.

(c) Absorption from Contaminated Wounds.--Contaminated wounds have constituted a much more troublesome problem than either gastrointestinal absorption or absorption through the unbroken skin. There are two aspects to the contaminated wound problem. If the plutonium is allowed to remain in the wound, it may (a) elicit a chronic local response, and (b) it will be slowly translocated to other tissues and organs, thereby contributing to local exposure of adjacent tissues and to an increased systemic burden.

Studies of absorption from contaminated wounds inflicted in experimental animals show great variations. These variations are not surprising. It is virtually impossible to reproduce or to 
standardize the characteristics of a wound, and if standardization of a wound could be accomplished the probability that one sustained in an accident would have the same characteristics would be slight indeed. Many of these observations, however, are of considerable qualitative significance. Plutonium applied as the oxide to abrasion-type lesions is absorbed very little, if at all. The material is trapped in tissue exudate, is thereby mobilized in the eschar, and lost when the eschar is detached [13]. Contamination of more substantial wounds, however, results in local deposition in the tissues and slow absorption into the systemic circulation. Qualitatively at least, it seems that $\mathrm{PuO}_{2}{ }^{++}$ is absorbed most rapidly from sites of intramuscular injection, $\mathrm{Pu}^{+3}$ next, and $\mathrm{Pu}^{+4}$ least rapidly [14]. The presence of conplexing agents such as citrate enhances the absorption rate. The absorption rate might be expected to depend also on depth of the wound and vascular and lymphatic circulation in the immediate area. Oakley and Thompson [11] studied the relative absorption of $\mathrm{Pu}\left(\mathrm{NO}_{3}\right)_{4}$ in $0.1 \mathrm{~N} \mathrm{HNO}_{3}$ through intact skin, through dermal cuts $(1.5 \mathrm{~cm}$ long), through comparable subcutaneous cuts, and from subcutaneous injection in rats and foind the amount of systemic absorption at 24 hours to be $0.33,0.55,0.95$, and 2.7 per cent, respectively. Variations in the nature, location or depth of the wound, difference in chemical nature of the solution and form of the plutonium, or use of a different species probably would have produced quantitatively different results. practically speaking, the most important feature of such observations is that they show a relatively slow rate of translocation regardless of chemical form of the plutonium, nature of the solution, and character of the wound. Under the more usually anticipated conditions of exposure, from about 70 to 95 per cent of the plutonium may be confined to the locality of the wound 4 to 10 days after infliction. This affords an opportunity to assess the seriousness of contamination and to judge the feasibility and value of surgical intervention. 
(d) Inhalation and Pulmonary Absorption.--The ultimate fate and biological effects of inhaled plutonium are dependent on the kinetics of deposition, retention, distribution, and absorp-tion of the inspired material. The kinetic parameters of these factors are dependent on a large number of interrelated physical, chemical, and biological variables, all of which are difficult to control and to evaluate experimentally. Among the most troublesome variables are particle size, particle density, aerosol concentration, chemical form and solubility of the plutonium, respiratory rate, tidal volume, and the animal species.

Bair and associates of the Hanford laboratory are making a concerted. effort to study effects of some of these variables on the kinetics of inhaled plutonium in beagles [15-20]. Their studies to date have involved primarily effect of particle size and chemical form of the plutonium. Although these experiments have been nobly and carefully pursued, they are difficult and timeconsuming and results to date do not seem adequate to provide a basis for any quantitative refinement of the lung retention model adopted by the International Commission on Radiological Protection [21]. The ICRP model assumes that 25 per cent of the inhaled material is exhaled immediately, 50 per cent is deposited in the upper respiratory passages and subsequently swallowed, and 25 per cent is deposited in the lower respiratiory passages. If the material is soluble, the 25 per cent deposited in the lower recesses of the lung is absorbed into the systemic circulation. If the material is insoluble, half of the amount deposited (12.5 per cent of that originally inhaled) is rapidly eliminated via the bronchial tree and the other half is retained in the lungs with a half-time of 120 days, being eliminated via absorption into the body fluids.

The observations of the Hanford group and others definitely indicate, however, that absorption from the lung into the systemic circulation (with subsequent deposition in the bone, liver, kidneys, spleen, and other tissues) is only one facet of a much more complicated problem. The persistently high concentrations and long retention times in the lungs and pulmonary lymph nodes following 
inhalation may result in greater potential risk to these tissues than to the bone, etc., from systemic absorption.

\subsection{Plutonium Deposition and Distribution}

Early work on deposition and distribution of plutonium was predicated on the assumption that the potential hazard was a systemic one, that clearance and absorption from the gastrointestinal tract and pulmonary tissues would be relatively rapid, and once plutonium was absorbed into the circulation its distribution would be relatively independent of chemical or physical form and the route of entry: Intramuscular [14] and intravenous [5] injections were used, therefore, to establish tissue distribution patterns, and the results led to the conclusion that bone (which showed the highest concentrations under these conditions) was the critical tissue. Collection of data from a number of subsequent papers $[4,13,17,22-25]$ shows that deposition and distribution are highly variable and dependent on a variety of factors, including route of administration, chemical or physical form of the plutonium, and animal species. Several generalizations are possible from the collected data. Following intravenous injection, bone and liver are the primary organs of deposition. The ratio between bone and liver, however, is dependent on chemical composition of the solution, valence state of the plutonium, and its colloidal state. The rate and degree of hydrolysis and polymerization of plutonium upon contacting the body fluids are largely responsible for variations in distribution observed for different valence states, different solution compositions, and different routes of administration. Those factors favoring colloid formation result in higher concentrations in liver and spleen and lower deposition in bone. Plutonium absorbed from the gastrointestinal tract and from intramuscular injection is deposited predominantly in the skeleton, as is highly complexed material administered intravenously. Plutonium absorbed from the lungs is deposited both in the liver and bone, with the relative distribution showing dependence on chemical form, solubility, and particle size of the inhaled 
material. The tissues with the maximum concentrations, however, are the lungs and pulmonary lymph nodes. Fragmentary autopsy data from workers who may have been chronically exposed to lowlevel plutonium inhalation [13] tend to support the high accumulation in lungs and lymph nodes observed in experimentally exposed animals.

\subsection{Plutonium Elimination}

(a) Systemic Burden.--It would be naive indeed to expect the rate of elimination of plutonium from the body to be independent of animal species, chemical and physical.nature of the material administered, and route or method of administration. The effects of these factors on elimination rates have been observed in a number of experiments.

The excretion rate of systemically absorbed plutonium is extremely slow and decreases with time. This time dependence has resulted in the general practice of expressing excretion rates as logarithmic functions of the type,

$$
\mathrm{Y}=\mathrm{a} \mathrm{T}^{-\mathrm{b}}
$$

where $\mathrm{Y}$ is the amount of plutonium excreted per day, and $\mathrm{T}$ is $t$ ime of observation in days after administration. Only limited consideration of some of the results in dogs and man will be given.

Stover et a1. [24,26] observed the excretion rate of intravenously administered $\mathrm{Pu}^{+4}$ citrate in beagles for periods up to 8 years after injection. They found that 12 per cent of the injected dose was excreted during the first 22 days, after which the rate leveled off rather abruptly. This necessitated fitting the data prior to and beyond 22 days with separate expressions. From 1 to 22 days after injection, the urinary $\left(\mathrm{Y}_{\mathrm{u}}\right)$ and total $\left(\mathrm{Y}_{\mathrm{t}}\right)$ plutonium excretion rates (in per cent of injected dose) were best represented by, 


$$
\left.\begin{array}{ll}
\mathrm{Y}_{\mathrm{u}} & =1.44 \mathrm{~T}^{-1.52} \\
\text { and } & \mathrm{Y}_{\mathrm{t}}=6.98 \mathrm{~T}^{-1.59}
\end{array}\right\}(1<\mathrm{T} \leq 22)
$$

Beyond 22 days, the urinary and total excretion rates were best represented as,

and

$$
\left.\begin{array}{l}
\mathrm{Y}_{\mathrm{u}}=0.0605 \mathrm{~T}^{-0.409} \\
\mathrm{Y}_{\mathrm{t}}=0.223 \mathrm{~T}^{-0.485}
\end{array}\right\}(\mathrm{T}>22)
$$

During the first 22 days, the fecal-to-urinary ratio dropped rapidly but averaged approximately 4 . Beyond 22 days, it was approx imately unity out to about 4 years.

Human excretion data have been obtained from occasional cases of occupational exposure and from 15 terminal patients administered tracer doses of plutonium (usually $\mathrm{Pu}^{+4}$-citrate) via intravenous injection. The latter observations have been summarized in a number of publications $[6,27,13,28]$. No attempt will be made here to present these observations in detail or to elaborate on their shortcomings and applicability to assessment of plutonium body burdens in man. It seems adequate only to say that their primary virtue lies in the fact that they are the only data of their kind available. To some degree, excretion of intravenously administered plutonium by man and dog is similar. The human urinary $\left(\mathrm{Y}_{\mathrm{u}}\right)$, fecal $\left(\mathrm{Y}_{\mathrm{f}}\right)$, and total $\left(Y_{t}\right)$ excretion rates (in per cent of injected dose) from 1 through 138 days were fit to the following power functions:

$$
\left.\begin{array}{l}
Y_{u}=0.23 \mathrm{~T}^{-0.77} \\
Y_{f}=0.63 \mathrm{~T}^{-1.09} \\
Y_{t}=0.79 \mathrm{~T}^{-0.94}
\end{array}\right\}(1<\mathrm{T} \leq 138)
$$


Additional data collected from three industrial exposure cases were used to adjust these expressions to $\mathrm{T}=\sim 5$ years. The adjusted expressions for the urinary and total excretion rates were:

$$
\text { and } \left.\quad \begin{array}{l}
\mathrm{Y}_{\mathrm{u}}=0.2 \mathrm{~T}^{-0.74} \\
\quad \mathrm{Y}_{\mathrm{t}}=0.79 \mathrm{~T}^{-0.94}
\end{array}\right\} \quad(1<\mathrm{T}<1750)
$$

Appreciably different expressions are obtained when the data are fitted in the normal instead of the logarithmic plane. The amount of plutonium excreted during the first few days was less for man than for the $\operatorname{dog}(\sim 3$ per cent as compared to 12 during the first 22 days). As with dogs, there was a very rapid drop in the rate during the first 20 to 30 days, after which it leveled off abruptly. In fact, a considerably better fit to the data is obtained if the excretion values during the first 10 days are excluded. As with dogs, the fecal-to-urinary ratio was about 4 immediately after injection and dropped to unity during the first 20 to 30 days. The ratio continued to drop, however, to a value of about 0.5 at 138 days.

(b) Lung Burden.--There are no experimental data on rate of elimination of inhaled plutonium by man. Observations are confined to a few cases of accidental industrial exposure [29, 30]. Elimination of material deposited in the lungs involves two routes: (a) absorption into the systemic circulation and subsequent excretion via the kidney and gastrointestinal tract, and (b) movement up the bronchial tree and subsequent elimination via the feces. The rates of elimination by both routes (as well as the amount initially retained in the lung) are dependent, of course, on the chemical and physical nature of the material inhaled and on the respiratory variables of the host. Retention or elimination of inhaled plutonium in various forms has been studied in mice, rats, dogs, and pigs. There appears to be little consistency in 
the data, in the experimental methods used, or in the methods of reporting results. No attempt is made, therefore, to summarize all of these studies. Among the more recent observations are those of the Hanford group [16-18,31] on beagles inhaling $\mathrm{PuO}_{2}$. In one of these studies [31], $\mathrm{PuO}_{2}$ doses were large enough to produce mortality in 55 to 412 days. From these observations, the authors deduced that beyond 2 weeks the total body retention was represented by the expression,

$$
p=A e^{-k t} \quad(t \geq 14)
$$

where $p$ is the whole-body burden at time $t$ in days after exposure, and $A$ is the initial amount deposited (at $t=0$ ) and excreted with the rate constant $k$. Evaluation of the constants gave a "typical". whole-body retention curve of,

$$
p=38 e^{-0.00084 t} \quad(t>14),
$$

for a large acute inhalation exposure to $\mathrm{PuO}_{2}$ particles of $0.5-$ to $0.65-\mu$ count median diameter. Since 95 per cent of the plutonium recovered at autopsy was found in the lungs, 4 per cent in the bronchial and mediastinal lymph nodes, and only about 1 per cent in the rest of the tissues, the first derivative of this expression may be assumed to represent the rate of clearance (under these specific conditions) of $\mathrm{PuO}_{2}$ from the critical pulmonary tissues of dogs. Both $A$ and $k$ in the general expression will vary with the chemical and physical nature of the inhaled plutonium, the aerosol concentration, and the respiratory variables of the host.

\section{Assessment of Plutonium Body Burden in Man}

An excelient review of the problems and methods of evaluating plutonium exposures in man has just been published by Robertson and Cohn [32]. Their article has been used repeatedly and without specific reference in preparation of the following sections. 
(a) Systemic Burden.--As mentioned previously, very early in the development of the United States plutonium project it was assumed that, regardless of mode of exposure, plutonium would be rapidly translocated to the skeleton and production of bone sarcoma would be the major potential industrial hazard. This assumption prompted development of a systemic model (based on excretion of intravenously administered plutonium by terminal hospital patients) for assessment of body burden from urine analyses $[13,27,28,33]$.

Following a single acute exposure occurring at known time, the body burden may be estimated from the plutonium content (U) of a 24-hour urine specimen (or the average of a series of consecutive samples) collected $T$ days after exposure by the following expression derived from Eq. 9:

$$
\mathrm{D}_{\mathrm{E}}=500 \mathrm{UT}^{0.74}
$$

$D_{E}$ is the body burden at time of exposure in whatever units $(\mathrm{d} / \mathrm{m}$, $\mu \mathrm{C}$, or $\mu \mathrm{g}$ ) used to express $\mathrm{U}$. The retained body burden $\left(D_{R}\right)$ at the time of the urine sample ( $T$ days after exposure) is given by the expression,

$$
\mathrm{D}_{\mathrm{R}}=435 \mathrm{UT}^{0.76}
$$

Industrial operations, however, usually involve intermittent or continuous low-level exposure, and attempts have been made to develop computer programs (on the basis of the systemic mode1) to estimate body burdens under these conditions. A program developed by Lawrence [34] assumes the body burden due to each individual exposure can be described by Eq. 9. He then estimates a series of single intakes that would produce the observed urine concentration. He uses a method of validating the data as follows. The urinary output on a given day is used to compute the expected output on any later day. If the output on the later day is lower than expected, the previous data point is rejected. This is done on the 
basis that if there is an additional intake between the two days the output should be higher; in no case should it be lower. This system then assumes that the most recent data point is a valid one. The major failing of this system is that a sample subsequently found to be invalid is capable of validating the immediately previous sample.

Snyder [35] has reported two codes, PUQUAP and PUQUAE, for estimation of body burden under chronic exposure conditions. His programs avoid the problem of rejection of data by assuming intake into and excretion from the blood are continuous functions of time rather than discrete quantities. These too are based on the power function expression shown in Eq.9. The assumption that the power function derived from the available data is sufficiently accurate that the integral will describe the case for continuous exposure is the greatest uncertainty in Snyder's approach.

It is important to point out that the body burden estimated from urine analyses by these codes does not include plutonium in the lungs and lymph nodes or material retained locally at the site of a contaminated wound. Furthermore, the presence of such reservoirs of unabsorbed plutonium may alter the parameters of the urinary excretion function. This has resulted in a number of reports pointing out limitations of the systemic model as a basis for diagnosing body burden and showing urinary excretion patterns that fail to conform to the power functions represented in Eqs. 6$10[29,30,36-38]$. In some of these cases, the excretion patterns were complicated by administration of agents to enhance elimination.

(b) Lung Burden.--Interpretation of urine analyses on the basis of the systemic model does not include material deposited in the lung and furthermore does not give a dependable estimate of the systemic burden because of influence of absorption from the lung reservoir on the urinary excretion pattern. Healy [29] has proposed a lung exposure model which attempts to take these factors into consideration. He assumes that plutonium deposited in 
the lung constitutes a reservoir of material isolated from the body's normal metabolic pathways but continually being absorbed into the systemic circulation at a rate dependent upon the physical and chemical nature of the deposit and relevant physiological processes. As the material is removed from the lung either by absorption into the blood or by excretion up the bronchial tree, the size of the reservoir, and thus the amount absorbed into the blood, decreases. Assuming exponential removal of the lung burden, the quantity of plutonium remaining (Q) at time $t$ following an acute fixation of a quantity $Q_{0}$ is given by the expression,

$$
Q=Q_{0} e^{-\lambda t}
$$

In this expression, the over-all elimination rate $\lambda$ is regarded as being composed of two components: (a) solubilization and absorption into the systemic circulation $\left(\lambda_{S}\right)$, and (b) removal via ciliary action $\left(\lambda_{c}\right)$. $Q_{0}$ specifically refers to that amount of plutonium retained in the lung after the initial rapid clearance of material deposited in the upper bronchial passages. Healy assumed that Eq. 9 describes the urinary excretion rate of each increment entering the blood and that the sum of the excretion rates of each increment gives the total excretion. It is important to note, however, that the time since administration in Eq. 9 must be taken as the time since the plutonium entered the blood and not as time of deposition in the lung. On this basis, if $R$ is the time of collection of the urine sample following deposition in the lung, then the resulting urinary excretion rate $\left(E_{u}\right)$ is given by,

$$
E_{u}=0.002 \lambda_{s} Q_{0} \int_{0}^{R} e^{-\lambda t}(R-t)^{-0.74} d t . \quad \text { (Eq. 16) }
$$

For convenience, the terms of this expression are collected and redefined as follows:

$$
\begin{aligned}
\mathrm{E}_{\mathrm{u}} & =\text { daily excretion rate } \\
\lambda & =\text { over-a1l elimination rate from the lung } \\
\lambda_{\mathrm{S}} & =\text { rate of transfer to the blood (assumed equal to } \lambda \text { ) }
\end{aligned}
$$




$$
\begin{aligned}
Q_{0} & =\text { quantity of plutonium retained in the lung after initial } \\
\text { rapid clearance } & \\
\mathrm{R} & =\text { sampling time following deposition in the lung } \\
\mathrm{t} & =\text { time since absorption into the blood stream }
\end{aligned}
$$

Since the expression is not integrable, it was evaluated for individual values of $\lambda, R$, and $t$ by expansion of the exponential term and solving until the series converged. Healy derived similar expressions for fecal excretion and for the quantity of plutonium in the blood as a result of movement from the lung.

When exposure is via inhalation, use of this model appears to be far more realistic than use of the systemic model. Its primary difficulty lies in the choice of proper values for $\lambda$ and $\lambda_{s}$ in view of their dependence on the physical and chemical nature of the lung deposit, which may not be known under actual exposure conditions, and on relevant physiological processes in the lung which are poorly understood at present. Healy found it necessary to assume $\lambda_{\mathrm{s}}$ equal to $\lambda$, and in applying the expression to an actual exposure case found that the rate of change in excretion was insufficient to provide an accurate estimate of $\lambda$, although samples were obtained for 1600 days. Figure 1 shows the fractional urinary excretion rate of plutonium on the basis of the two models, assuming a unit body burden is deposited systemically in the case of the systemic model and in the lung for the lung deposition model. In the latter case, $Q_{0}$ is assumed equal to unity and calculations are shown for $\lambda_{s}=0.01$ $(\mathrm{T} / 2=69$ days $)$ and $0.001(\mathrm{~T} / 2=693$ days $)$. A number of pertinent points may be deduced from Fig. 1. First, the data show that the level of urinary excretion following inhalation exposure is dependent on $\lambda_{\mathrm{s}}$ which is related to the solubility of the material inhaled. Second, the rate of urinary excretion may remain essentially constant or actually increase for a period of time (inversely proportional to $\lambda_{S}$ ), after which it may begin to decrease with a slope greater than that expected from the systemic model. Third, the urinary excretion pattern following significant lung deposition cannot be expected to conform to that following intravenous injection for a period after exposure that is inversely proportional to $\lambda_{s^{*}}$ Qualitatively at least, it may be assumed that no significantly large lung burden exists if the slope of the urinary excretion curve is essentially the same as 


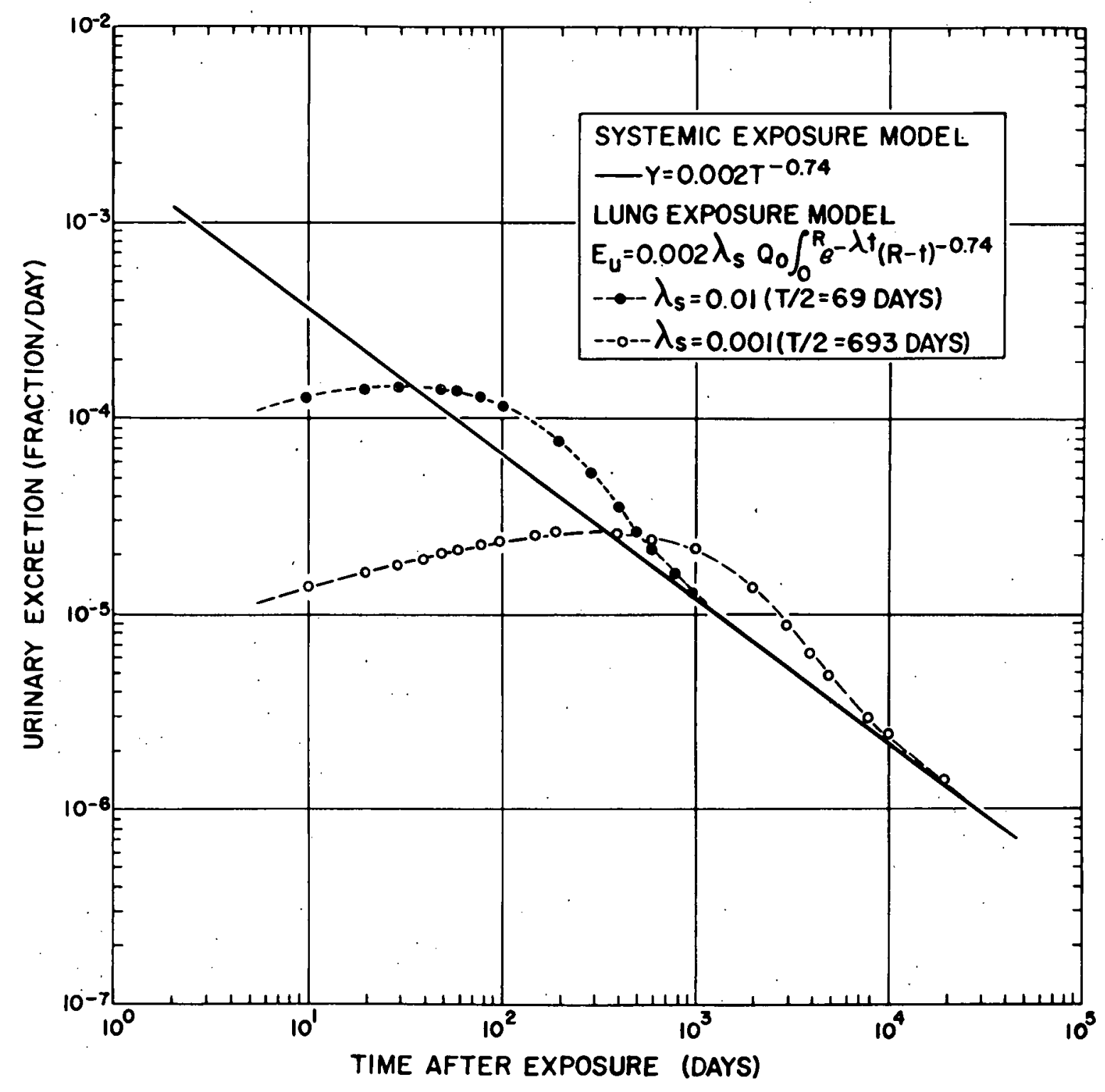

Fig. 1. Fractional urinary excretion as a function of time after acute exposure based on the systemic and lung exposure models. 
that expected on the basis of the systemic model. The same may be assumed regarding unabsorbed material in cutaneous or subcutaneous wounds. A lesser slope at early times after exposure or a greater slope at later times may be considered indicative of a reservoir of unabsorbed plutonium in the lungs or at the site of a contaminated wound. The question is whether $Q_{0}$ can be estimated from urine analyses on the basis of the lung exposure model. In theory, it seems possible if $\lambda_{s}$ is known for the specific conditions of exposure. Such an approach to estimation of lung burden under actual plant conditions may not be feasible because of practical limitations.

It would appear more promising in future work, however, to attempt to apply and refine the lung deposition model and to design experiments to better evaluate $\lambda$ and $\lambda_{s}$ and their dependence on appropriate physical, chemical, and biological factors than to continue to apply the systemic model to situations for which it is not adequate.

This author [27] attempted at one time to develop a method of diagnosing lung burden from urinary-to-fecal excretion ratios. The difficulties of collecting and analyzing fecal samples and the wide fluctuations in fecal excretion, plus its dependence on physical. and chemical nature of the deposited material and on ill-defined processes of pulmonary elimination, make the method quantitatively useless. About all that can be said is that fecal-to-urinary excretion ratios may be used in a qualitative sense to determine whether appreciable pulmonary exposure has occurred.

\subsection{Body Burden by External Counting}

(a) Systemic and Lung Burden.--The fact that plutonium emits electromagnetic radiations has stimulated attempts to develop external counting methods of determining body burdens. Detection of plutonium in vivo by whole-body counting has been reviewed by Roesch and Palmer [39]. Conventional whole-body counting techniques cannot be applied to the measurement of $\mathrm{pu}^{239}$ body burdens. This is because the characteristic electromagnetic radiation from $\mathrm{Pu}^{239}$ consists predominantly of soft $X$ rays. There are only a few low 
energy gammas. The relatively abundant $X$ rays are easily absorbed, the half-value layer in tissue being $\sim 0.6 \mathrm{~cm}$ and in bone $\sim 0.03 \mathrm{~cm}$. This makes accurate quantitative measurements extremely difficult. With the quite low half-value layer in bone, the quantitation of skeletally deposited plutonium by external measurements is highly unlikely.

Whole-body counting has been applied to measuring plutonium in the lungs and in the liver. Rundo and Taylor [40] have used a gas flow proportional counter (argon and methane mixture) with a $150 \mathrm{~cm}^{2}$ thin Lucite window for measuring plutonium in the lungs. For a counting time of 50 minutes, with a source-to-detector distance of $10 \mathrm{~cm}$ and shielding of $2.54 \mathrm{~cm}$ of tissue, the minimum detectable amount of plutonium is about $15 \mathrm{nc}$.

Roesch, et al1. [39] have used a thin NaI (T1) crystal, $11.5 \mathrm{~cm}$ in diameter by $0.1 \mathrm{~cm}$ in thickness, to measure plutonium in the liver of a subject. The minimum detectable body burden was estimated to be 300 nc. The errors in the measurements are, of course, quite large. They report somewhat better success using a crystal thickness of $0.3 \mathrm{~cm}$ and measuring the gamma rays from $\mathrm{Am}^{241}$ present in the plutonium.

Kiefer and Maushart [41] have used annular cylindrical proportional counters to measure plutonium in the hand or arm. They report being able to detect 20 nc distributed in a phantom arm. They suggest that large flat anticoincidence proportional counters might be used to measure plutonium in the lungs. Such a system has not yet been attempted.

(b) Burden in Contaminated Wounds.--Contamination of wounds has been a significant industrial health control problem. As with material deposited in the lungs, urine analyses cannot be relied on to determine quantitatively plutonium localized at the site of a contaminated wound. Early detection and subsequent surgical removal (when feasible) of such implants have become more or less standard practice [42]. External counting procedures have been developed to determine the amount of plutonium in such implants 
by measuring the $17-\mathrm{Kv} X$ rays $[43,44]$. If the material is superficially deposited, these counters have a minimum detectable level of about $0.1 \mathrm{nc}$.

\section{Discussion and Conclusions}

Twenty years experience with the production and processing of large quantities of plutonium in the United States has shown the primary industrial hygiene problems to be chronic or intermittent low-level inhalation exposure, a number of contaminated wounds, and a few accidental acute exposures usually involving inhalation. The industrial medical record of the plutonium industry appears almost miraculous. Perhaps fewer than 50 workers have received exposures equal to or slightly greater than the maximum permissible body burden, insofar as it is possible to assess a body burden. This enviable record is a result of the rigorous industrial hygiene and engineering control measures introduced into plutonium processing operations from the very beginning.

With such rigorous and effective industrial hygiene controls, one may question seriously the value of a difficult and expensive routine program of assessing body burdens of parsonnel working with plutonium. This is not an easy question to answer. However, a workable program of this nature would provide the ultimate proof of the effectiveness of industrial hygiene control measures. Both the Hanford and Los Alamos laboratories have uncovered potentially hazardous operations and exposure conditions through investigating high urinary excretion values of specific employees. Also, if it were possible to determine body burden with reasonable accuracy, such a program would be highly desirable both for health protection and for medicolegal reasons. In the opinion of this author, present capability of assessing body burden is limited to assessment of systemic burden from urinary excretion to $\pm \sim 25$ per cent following an acute exposure under conditions that preclude any significant reservoir of unabsorbed material in the lungs or tissues. Even under these simple conditions, this accuracy cannot be obtained from a simple routine sampling schedule but requires careful analyses of 
a series of 24-hour specimens collected over a period of several weeks.

At the present time, there is no proven method for assessing body burden in those cases where significant reservoirs of unabsorbed material may be localized in lungs and lymph nodes. It is possible, however, to use the fecal-to-urinary ratio to establish the presence of a sizable pulmonary reservoir following an acute inhalation exposure. A ratio of several times unity clearly indicates unabsorbed material in the lung. Unfortunately, the ratio cannot be related quantitatively to the size of the lung burden. It is possible also to establish qualitatively the presence or absence of a significant lung burden from the general characteristics of the urinary excretion pattern.

More critical than the occasional acute exposure case, which is always given special consideration, is the problem of the longterm employee. The Los Alamos Scientific Laboratory now has several employees who have been working with plutonium for over 10 years. Many of these have no history of involvement in a contamination accident, exposure to excessive air concentrations, or infliction of a potentially contaminated wound. They, however, consistently show positive plutonium excretion in the urine. Estimation of their body burdens by the IBM 704 FORTRAN code developed by Lawrence [34] gives values ranging from 25 to 100 per cent of the maximum permissible level. It has not been possible to test the accuracy of such codes for the estimation of body burden under the conditions of very low-level chronic exposure experienced by these workers. The extent of lung and lymph node accumulation under these conditions is an unanswered question also.

In conclusion, it may be said that there is no known satisfactory method of assessing plutonium body burden in man under the more usually encountered conditions of exposure. The greatest needs are for a nethod of determining body burden under conditions of very low-level chronic and intermittent exposure and a method of assessing the amount of material deposited in the pilmonary tissues. Development of methods based on external measurement of the 17-Kv $X$ rays from plutonium may be the most promising approach to the latter need. 


\section{References}

[1] SEABORG, G. T., MCMILLAN, E. M., KENNEDY, J. W. and WAHL, A. C., Phys. Rev. 69 (1946) 366/367.

[2] HAMILTON, J. G., Radiology 49 (1947) 325/343.

[3] KATZ, J., KORNBERG, H. A. and PARKER, H. M. , Am. J. Roentgenol. 73 (1955) 303/308.

[4] WEEKS, M. H., et al., Radiation Res. $\underline{4}$ (1956) 339/347.

[5] CARRITT, J., et al., J. Biol. Chem. 171 (1947) 273/283.

[6] LANGHAM, W. H., Health Phys. 2 (1959) 172/185.

[7] WILSON, R. H., Hanford Atomic products operation, General Electric Company, USAEC Report HW-42030 (1956).

[8] WEEKS, M. H. and OAKLEY, W. D., Hanford Atomic products Operation, General Electric Company, USAEC Report HW28636 (1953) 85/91.

[9] WEEKS, M. H. and OAKLEY, W. D., Hanford Atomic products Operation, General Electric Company, USAEC Report HW30437 (1954) 102/105.

[10] WEEKS, M. H. and OAKLEY, W. D., Hanford Atomic products operation, General Electric Company, USAEC Report HW35917 (1955) 56/63.

[11] OAKLEY, W. D. and THOMPSON, R. C., Hanford Atomic Products Operation, General Electric Company, USAEC Report HW41500 (1956) 106/113.

[12] BALLOU, J. E. and OAKLEY, W. D., Hanford Atomic Products Operation, General Electric Company, USAEC Report HW47500 (1957) 142/145.

[13] LANGHAM, W. H., et al., Health Phys. 8 (1962) 753/760.

[14] SCOTT, K. G., et al., J. Biol. Chem. 176 (1948) 283/293.

[15] BAIR, W. J., in Inhaled Particles and Vapours, pergamon Press, London (1961) 192/207.

[16] BAIR, W. J. and McCLANAHAN, B. J., Arch. Environ. Health 2 (1961) 648/655.

[17] BAIR, W. J. and WILLARD, D. H., Health Phys. 8 (1962) $639 / 649$. 
[18] BAIR, W. J. and WILLARD, D. H., Health Phys. 9 (1963) $253 / 266$.

[19] BAIR, W. J., Hanford Atomic Products operation, General Electric Company, USAEC Report HW-56663 (1958).

[20] BAIR, W. J., WILLARD, D. H. and WEST, J. E., Hanford Atomic Products Operation, General Electric Company, USAEC Report HW-6950O (1961) 67.

[21] MORGAN, K. Z., Report of ICRP on Permissible Dose for Internal Radiation, Health Phys. 3 (1960) 153.

[22] SMITH, V. H., et al., Proc. Soc. Exptl. Biol. Med. 107 (1961) 120/123.

[23] BUSTAD, L. K., et al., Health Phys. 8 (1962) 615/620.

[24] STOVER, B. J., ATHERTON, D. R. and KELLER, N., Radiation Res. 10 (1959) 130/147.

[25] ABRAMS, R., et al., University of Chicago, Metallurgical Laboratory Report $\mathrm{CH}-3655$ (1947).

[26] STYVER, B. J., et $\underline{\text { al }}$. ; Health Phys. 8 (1962) 589/597.

[27] LANGHAM, W. H., Am. Ind. Hyg. Assoc. Quart. 17 (1956) $305 / 318$.

[28] LANGHAM, W. H., Brit. J. Radiol., Suppl. 7 (1957) $97 / 113$.

[29] HEALY, J. W., Am. Ind. Hyg. Assoc. Quart. 18 (1957) $261 / 266$.

[30] SWANBERG, F., Jr., Health Phys. 8 (1962) 761/765.

[31] BAIR, W. J. and WILLARD, D. H., Radiation Res. 16 (1962) $811 / 821$.

[32] ROBERTSON, J. S. and COHN, S. H., Health Phys. (1964)

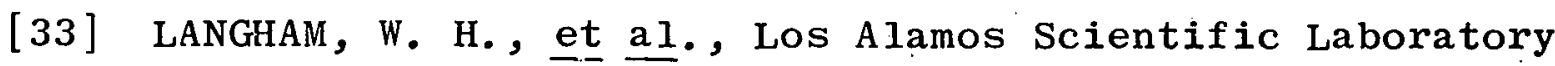
Report LA-1151 (1950).

[34]. LAWRENCE, J。 N. P., Health Phys. 8 (1962) 61/66.

[35] SNYDER, W. S., Health Phys. 8 (1962) 767/772.

[36 ] LISTER, B. H. J., MORGAN, A. and SHERWOOD, R. J., Health Phys. 9 (1963) 803/815.

[37] SANDERS, S. M. and AIKEN, S. C., Arch. Environ. Hea 1th $\underline{2}$ (1961) 474/483. 
[38] HAMMOND, S. E。, USAEC Research and Development Report WASH-1023 (1958) 84/100.

[39] ROESCH, W。C. and PALMER, H. E。, Health Phys。 8 (1962) $773 / 775$.

[40] RUNDO, J。 and TAYLOR, B. T., Personal communications quoted by Roesch and Palmer, preceding reference.

[41] KIEFER, H. and MAUSHART, R., Nucleonics 19(12) (1961) 51.

[42] NORWOOD, W. D., Health Phys. 8 (1962) 747/750.

[43] ROESCH, W. C. and BAUM, J. W., proceedings of the second International Conference on Peaceful Uses of Atomic Energy, Geneva, 23 (1958) 142.

[44] PUTZIER, E。 A., MANN, J. R. and JOHNSON, V. P., Am. Ind. Hyg. Assoc。 Quart. 19 (1958) 384/385. 